\title{
A BALLOON-BORNE DETECTOR FOR STRATOSPHERIC COSMIC DUST DETECTION
}

\author{
WAN GUCUN, OUYANG ZIYUAN, XU YIWEN, WU XIGUANG \\ Institute of Geochemistry, Academia Sinica, \\ Guiyang, Gaizhou Province, \\ People's Republic of China, 550002
}

ABSTRACT. This paper introduces a kind of cosmic dust collecting technique anddescribes in detail the structure of the collector, the balloon-basket system and concerning experimental skill.

\section{INTRODUCTION}

Cosmic dust is one of the material sources of the earth. Studies of cosmic dustis of great importance not only in exploring the origin and evolution of thesolar system and some small celestial bodies such as comets, but also in dis-cerning the environmental catastrophic events and extinction of living thing in the history of the earth, providing the scientific basis for the stratigraphic livision and correlation and calculating the flux of cosmic dust particles. It is still of practical significance in space exploration through the study of the composition, flux and distribution of cosmic dust.[1]

Although great advances have been made in modern aerospace technology, the high-altitude scientific balloon is still an important approach to collecting cosmic dust [2].

From 1984 to 1987, in order to establish some practical and effective experi-mental methods in collection of cosmic dust from the stsatosphere, we had done two flights in which our experiments were done on the trial basis and the collectors were attached to the balloon baskets for other experiments. Then, we did three flights in which we self-designed balloon baskets and collectors were used and the whole experiment process was established. The balloon lauching site is in Xianghe County, Hebei Province. Usually the flight altitude for col-lecting work were in $25000 \sim 35000 \mathrm{M}$ high. The radius of balloon level-flight was controled by telecontrol device in range of $150 \sim 200 \mathrm{KM}$.

\section{THE TYPE OF COLLECTOR AND ITS LOCATION}

According to the conditions of laboratory measurement and analysis, we are engaged mainly in the collection of cosmic dust particles measuring $10 \mu$ or more in grain size. So it is advised to use the settling-plate type collectors as a major approach. [2]

The location of the collectors in the balloon-basket system has a great bearing on the whole layout of the collectors, so at the initial stage of de-signing the location must be determined.Fig. 1.shows the location of our colle-ctors.

At the time the balloon goes up and the collectors open to work, the col-lectors are put on the two racks fixed on both sides of the basket. Once the collection is finished, the collectors are closed automatically. Before the basket and balloon are separated, the collectors are pulled into the

A.C. Levasseur-Regourd and H. Hasegawa (eds.), Origin and Evolution of Interplanetary Dust, 33-36. (1) 1991 Kluwer Academic Publishers, Printed in Japan. 
framework of the basket. Thus, at the time the basket goes down, there will occur no "rotor blade effect" (which is harmful to the work of parachute) and if the basket turns over or rolls after landing, the collectors still can be effectively protected by the framework of the basket. The experiments on high-altitude balloon collection of cosmic dust have shown that this approach is feasible and effective with respect to the function and recovery of the collectors.

\section{THE STRUCTURE OF THE SETTLING-PLATE COLLECTOR}

According to the flux introduced by D. E. Brownlee [2] and L. Hemenway [3], the surface collection area is determined to be $0.8 \mathrm{M}^{2}$.

The collector takes the form of double cassettes with the covers which can open and close. The collection surfaces made of a kind of transparent polyester film are coated on the inner surfaces of the covers and the bottoms made of hard aluminium plate $(2 \mathrm{~mm}$ thick). The cover and bottom of the collecor are equipped with the rectangular frame made of angle-shaped aluminium material and sealing material. When the cover of the collector cassette revolves and closes, the frame on the cover just hoods the rectantular frame on the bottom, constituting a labyrinthine structure. The sealing material is a kind of clean plastic foam. Before the balloon is launched, the foam should be smeared with clean silicone oil. Thus, when the cassette colses and the basket falls to the ground from the space, the ventilation of plastic foam makes the inner pressure of the cassette keep up with the outside pressure. On the other hand, plastic foam smeared with silicone oil can effictively prevent pollutant particles from finding their way into the collector cassette.

Journal bearings are adopted in the mechanical tranmission system of the collectors. Inthe system there is no need to apply lubricant so as to avoid some possible troubles brought about by lubricating-oil at lower temperature.

As an adhesive agent to the collector, freezeproof clean silicon oil is coated on the collection surfaces.

As the collectors are easy to dismount from the basket on the landing spot, the collectors can be recovered without pollution.

\section{THE STRUCTURE OF THE BASKET AND THE BALLOON-BASKET SYSTEM}

The basket has a rectangular frame made of angle-shaped steel. According to the technical requirements, the racks are fixed on both sides of the basket frame. The rigid slideways are welded in the basket on the frame and linked up with the racks. There still fix limit switch and rope towed mechanism which can pull the collectors into the basket.

We fix miniature permanent magnets on the ends of the base plates and racks. Thus, even though the basket slants at $30^{\circ}$, the collectors will not slide. The towed force of the motor is enough. The motor which tows the ropes is a torque motor manufactured in Beijing Micromotor Factory. Through the deceleration of the transmission system, the base plate of the collectors can get a speed of about one metre per minute to remove smoothly. The ropes we used are those of 8020-type parachute. So under lower temperature and high altitude conditions, their strength is reliable.

Fig. 1 Shows the positions of all the apparatuses in the basket. Some heavy apparatuses such as storage battery and sand-throwing device are located at the bottom of the basket.

The lower chamber of the basket in which electrical facilities are located is sealed with $50 \mathrm{~mm}$ thick polystyrene foam plastic plate. The batteries are most sensitive to lower temperature so every group of batteries is sealed with $20 \mathrm{~mm}$ thick polystyrene foam plastic plate again.

According to the weight of the basket, we choose a kind of balloon whose volume is $30000 \mathrm{M}^{3}$. In order to reduce the "shielding effect of balloon" as small as possible in the flight and in regard to the bearing capacity of the balloon, the length of the ropes have to be $70 \mathrm{M}$. When the balloon goes up to the high altitude, its maximum diametre is $42.4 \mathrm{M}$ and its half height is $21.5 \mathrm{M}$ [4]. So the distance from the collection surface to the half height of the balloon is $105 \mathrm{M}$. The 
shadow half spread angle in the collector is $11.36^{\circ}$. Obviously this is acceptable.

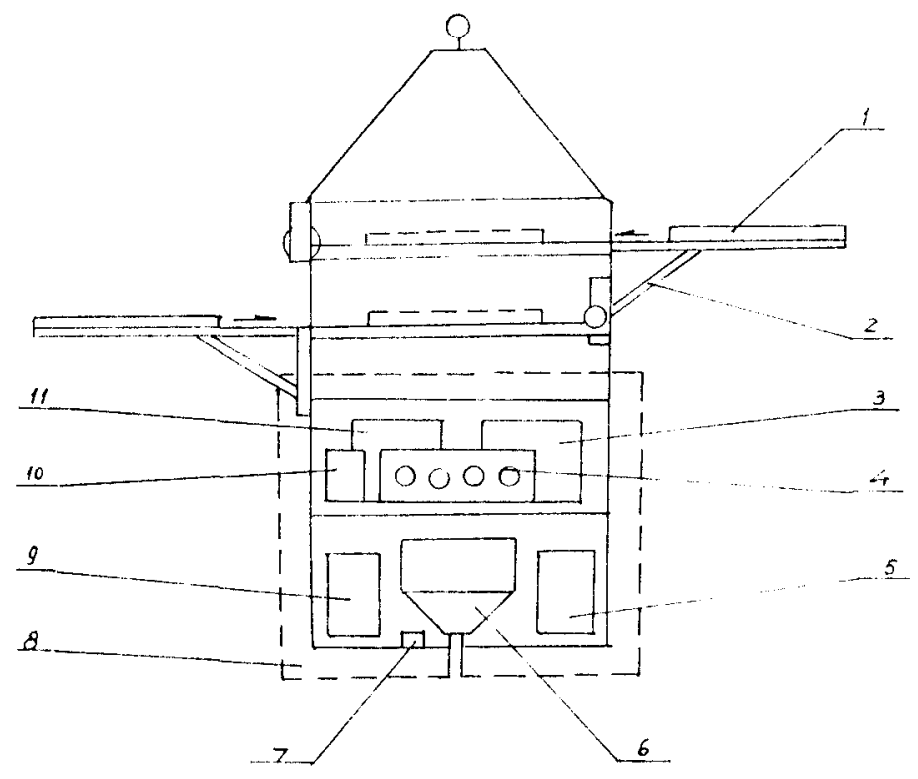

Fig. 1. Shows the positions of all the apparatuses in the basket.

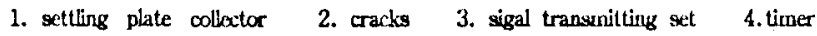
5. power A 6.sand-thowing device 7.antenna
8. thermal insulating kyer of polystyrene foam 9. power $B$
10. collectors controller 11. signal recriver

\section{CONCLUSIONS}

The high-altitude settling-plate cosmic dust collector designed by us has some outstanding advantages: It is simple in structure; it has a big enough collecting surface area; the surface of organic thin film is easy to clean; it is convenient to observe and select specimens under the microscope. During the flying of the balloon, the collecting facilities work normally. After the collectors are closed and pulled into the basket and land with it, under the protection of the frame, the collectors could be recoverd without any damage and the specimens will not be polluted. We have obtained some specimens in this way. Further studies will be published in anothe paper [5].

The collectors we designed and the method of locating them on the basket can also be used in the same practice in the future time. A set of feasible and effective experimental methods and techniques concemed are established.

\section{ACKNOWLEDGEMENTS}

Our experiments on high-altitued cosmic dust collection were carried out under the great help of the balloon engineering groups of the Institute of High Energy Physics and the Institute of Atmospheric Physics, Academia Simica. They provided the relevant devices of balloon engineering. The work on balloon launching, flight controlling and recovery was accomplished by them. Here we express our appreciation to them.

The project is financially supported by the National Natural Science Found-ation of China. 


\section{References}

[1] 欧阴自远(1988) 天体化学、科学出版杜, 北京PP. 273 .

[2] Brownlee,D.E. (1978) 'Studies by sampling techniques' in J.A. McDonnell (edit), Cosmic Dust, John Wiley and Sons, New York. PP. 225-335.

[3] Hemenway, C.L. et.al. (1967) High altitude balloon-top collection of cosmic dust', in Space Research,Vol.7. North-Holland, PP. 1423-1431.

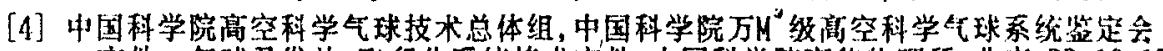
文件一一球及发放，飞行分系统技术文件，中国科学院培能物理所，北京，PP，12-15，34。

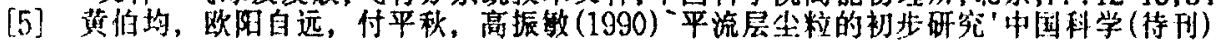

